\title{
Rational Embracing of Modern Prototyping Capable Design Technologies into the Tools Pool of Product Design Teams
}

\author{
Stamatios Polydoras, Michael Sfantsikopoulos, and Christopher Provatidis \\ School of Mechanical Engineering, National Technical University of Athens, 9 Iroon Polytechniou Street, 15773 Athens, Greece \\ Correspondence should be addressed to Christopher Provatidis, cprovat@central.ntua.gr
}

Received 31 January 2011; Accepted 13 March 2011

Academic Editors: A. A. Kendoush and W. Polini

Copyright () 2011 Stamatios Polydoras et al. This is an open access article distributed under the Creative Commons Attribution License, which permits unrestricted use, distribution, and reproduction in any medium, provided the original work is properly cited.

\begin{abstract}
Today's markets impose wide sets of requirements for new products. The Process of New Product Design, has shifted from sequential Engineering to Concurrent Engineering, for low cost—early market entry. Design Teams must deliver highest quality within minimum time and cost and global crisis worsens things, by further reducing budgets. Prototyping within design processes has become crucial, whereas, available prototyping alternatives have increased. Decisions regarding the use of the most appropriate one, at specific design milestones, affects and much predetermines the success of the product. This paper addresses the problem of "design target"-based embracing of available prototyping alternatives into the tools pool of design teams, in a concise, integrated way. Considering product design teams are expert driven for specific product categories, the introduced approach records the verification intent of designers and binds it to structured Generic Levels of Technical and non-Technical Attribute clusters and associated Design Factors. Furthermore, prototyping experience, manufacturing capabilities and cost of the implementing organization, local industrial status and regulations, are also considered. Utilizing the Analytic Hierarchy Process a complete decision tree leads designers to select the most appropriate prototyping method per design stage. The proposed approach assists implementing organizations and design teams towards cost/time benefits, product risk reduction, decision repeatability and independence. A pilot-model has been developed with "Expert Choice" software and an application example is discussed.
\end{abstract}

\section{Introduction}

Market globalization coupled with intense competition has nowadays led modern production to noticeable product differentiation, continuous shortening of product life cycles and lead times, and hence to the increasing demand for "right first time" manufacturing of high-quality, cost competent industrial products. Moreover, issues of environmental protection, related concerns, and newly imposed regulations have all during the last two decades led to a new form of the New Product Design and Development (NPDD) Process. In this form of NPDD, "Minimum" has acquired a whole new meaning, both as a goal for overall lead times and costs and also in terms of the new products' environmental impacts, especially after the recent global economic crisis [1-4].

This change is luckily supported by innovative and constantly improving technological tools made available to designers and engineers (e.g., [5-13, 15]).
Many approaches have been proposed to generally describe the New Product Development Process [14, 16-19]. In most of them the process is briefly summarized to the main stages of Idea Generation/Product Planning, Conceptual Design, Embodiment Design, Detailed Design, Process Planning and Manufacturing Preparation, Commissioning to production [20]. More recently, Design of Service, Design for End of Life, Design for Disassembly and Recycling steps are also included.

Design Teams, responsible for conforming to a new Product's Design Specifications (PDSs), are as a rule working within the frame of the Concurrent Engineering (CE) principles, where the main idea is to consider all aspects of the product, design, manufacturing, even selling, and recycling at the early stage of the design cycle and implement iterations and changes as early as possible, easily and effectively [21]. This of course causes design stages to overlap one another. It is worth noting that early design stages are acknowledged 
to be extremely important and may account for up to $70 \%$ of product costs, from as little as 3-4\% of the development costs $[22,23]$.

The degree of fulfillment and the successful transferring of the design intent on the actual product, as expressed by the Design Requirements (DRs) and the respective Design Attributes (DAs), decisively predetermines its success and has to be evaluated as early as possible already within the design process $[12,24]$.

Such assessment and evaluation is mainly performed through prototypes.

In addition to well-proven and established conventional prototyping methods that have been in use for decades (e.g., wood sculpted models, hand-drawn sketches), nowadays Information Technologies (ITs) support a considerable number of alternatives, which in a broader sense can be considered time and cost-efficient prototype solutions, such as 3D CAD models, FEA Simulations, Virtual Reality (VR), and Virtual Prototypes (VP) [7, 9, 11], as well as tangible object solutions like Rapid Prototypes and High Speed CNC machined parts.

As a consequence, Design Teams often face the dilemma of proper prototyping alternative selection [10]. This is not a predestinate decision, but rather a interdisciplinary one, depending both on the occurring design stage requiring a prototype as well as on the attributes to be verified by the design team at given time. Often such decisions are not systematic and are taken under pressure of deadlines and running costs, by and large based on intuition and/or on limited relevant experimental knowledge. Usually a fragment, only, of all information available is taken into account, which in turn introduces many risks.

\section{Role and Basic Categorization of Prototypes: Scope of the Paper}

A prototype can be defined as an artifact incorporating characteristics of the new product under development that enables designers to test various aspects of their ideas before committing themselves to the expense and risks of producing commercial quantities (hard tooling) [25]. Prototyping is meant to provide the design teams with information and insight to a variety of product technical attributes, grouped in three main areas, namely form, fit, and function.

Classification of prototypes with respect to their ability to serve the distinct stages of the design process introduces the following broad prototyping classes, $[26,27]$.

(i) Design/Aesthetic Prototypes, or, Design/Appearance Models, mostly representing form and analogies of the product.

(ii) Geometrical Prototypes, having all or most of the exact form features and dimensions of the product.

(iii) Functional Prototypes, further having similar or the exact material as the final product. (iv) Technical/Technological Prototypes, produced with similar or the exact production method and Prototype Tooling, where the focus is on attributes of the tools during manufacturing of the product.

(v) Preproduction items, used to fine tune parameters of the production methods and processes.

Until the near past (early 1980s) sketches, blueprints, and hand-crafted and conventionally machined models were, more or less, the full population of prototyping alternatives within the above categories.

With IT and Computer-Aided (CAx) applications blossoming in the 1980s and 1990s and now being well within the modern engineering curriculum, apart from the above classification (design models, geometrical, functional, technical), prototypes, often also named "mock-ups" or "models," can be further recognized to exist in "physical" or "virtual" essence, where a "physical prototype" is defined as a tangible real object of the material world, whereas a "virtual prototype" is a computer-generated digital representation, or even a simulation.

Figure 1 schematically depicts the involvement of the various modern prototype types in the design process.

Regardless of their characterization as traditional or contemporary, virtual or physical, the main "prototyping alternative" groups nowadays include hand-crafted and machined models, 3D CAD models and assemblies, CAE analysis and simulation models, Virtual Prototypes, Product Lifecycle Management (PLM) data, and Rapid Prototyping (RP) and Rapid Tooling (RT) models, [7, 9-11, 20, 28-32]. It can thus be acknowledged that the prototyping alternatives currently offered to designers and industrial operators (a) are indeed many in number, and, (b) although launching from different origins, they present definite overlap capabilities and applicability, especially as they all evolve during the years $[5,6,13]$.

Since all alternatives are often not readily available for a particular application, especially at Small and Medium Enterprises (SME) level, confusion and decision difficulties frequently arise. This situation is apparent in Figure 2, where the role of the main competing prototyping alternatives is schematically placed with respect to the stages of the design cycle, and compared in two different decades.

Design teams must be supported in this selection, in a methodological, concise, and unbiased way that will consider both engineering and nonengineering parameters driving the prototyping decision, being at the same time comprehensive and documented.

SMEs especially are much in need of such support, since they are more sensitive and vulnerable when it comes to prototyping selection decisions, being usually restricted in terms of funds and engineering means when compared to large organizations and enterprises.

The problem of a systematic prototyping selection has been recognized and addressed in several ways, [10, 3336], with varying effectiveness as a consequence of the everincreasing number of the selection issues, the prototyping technologies, and the rapid changes in the overall new product design and development specifications. 


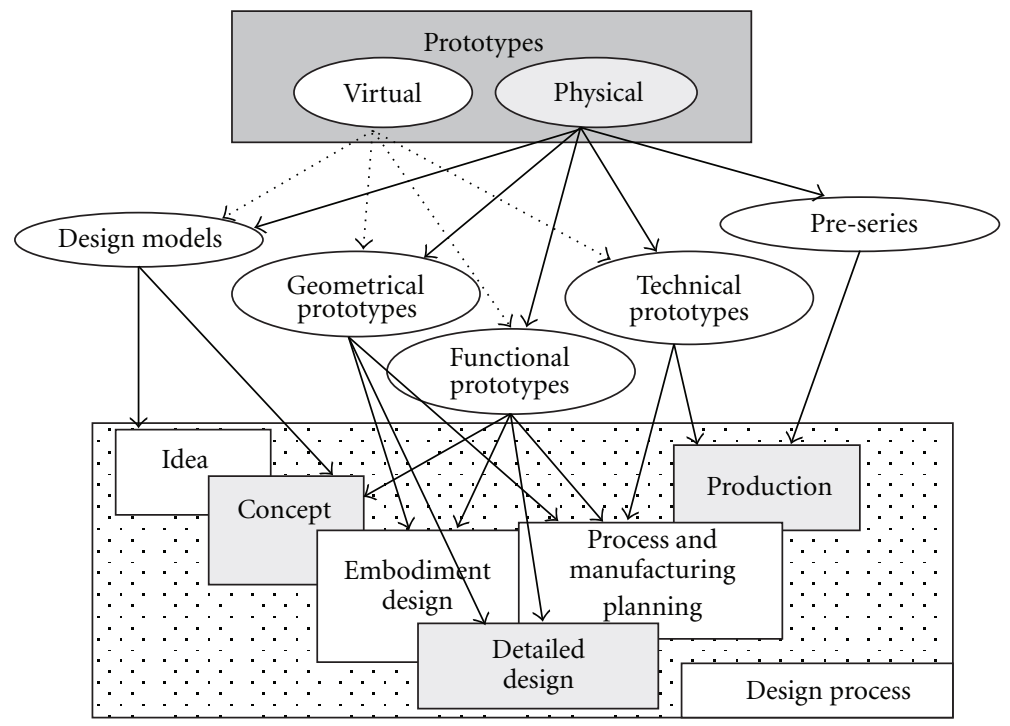

FIGURE 1: Involvement of prototypes in the design process.

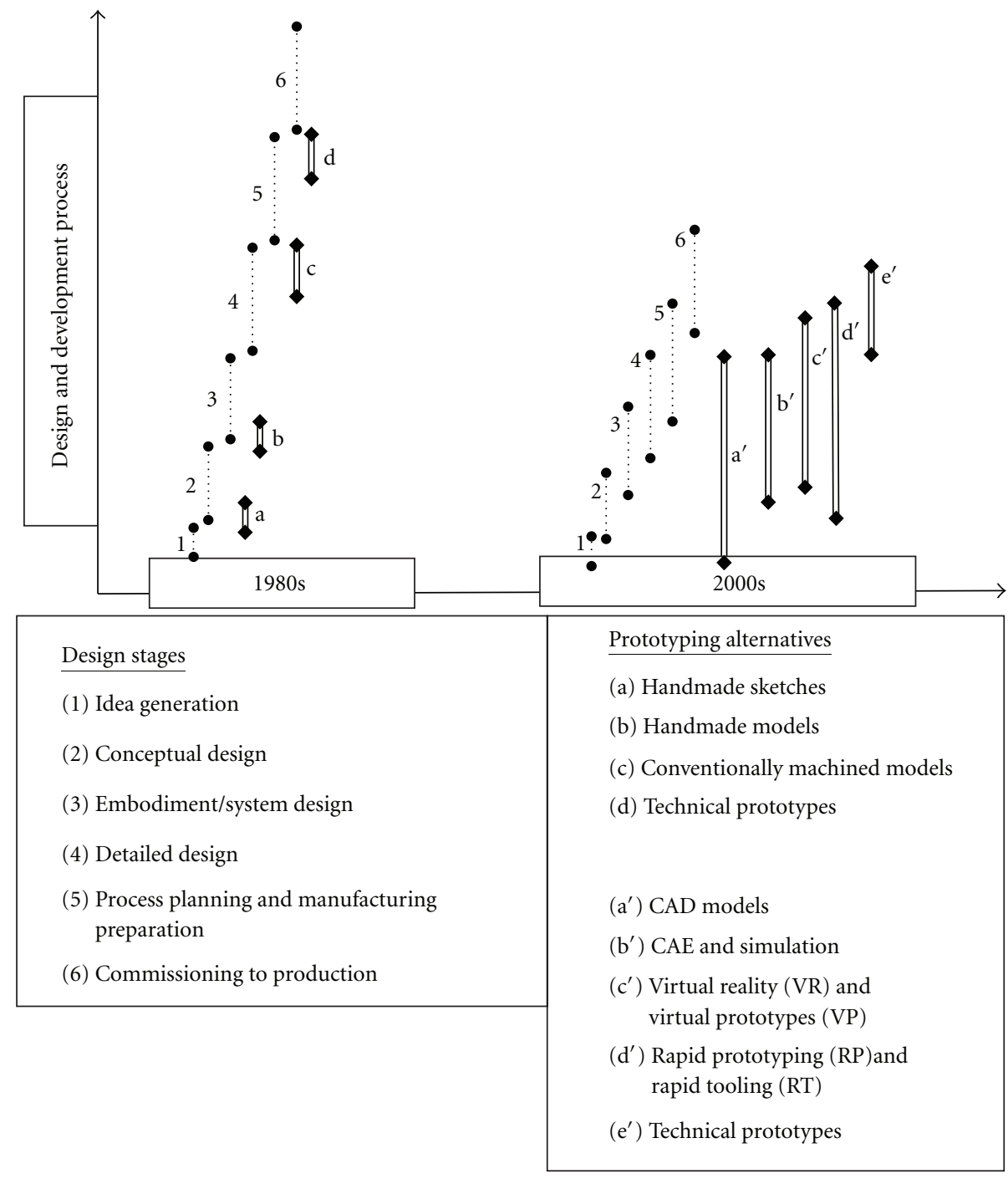

FIGURE 2: The overlap of modern prototyping alternatives in the design process. 
In this paper the authors introduce an extended, enhanced, and integrated prototyping alternative selection approach that, in a rational way and for the first time, on one hand recognizes and considers for evaluation all virtual or physical prototyping capable modern design technologies and on the other hand incorporates widely accepted and adopted technical attribute groups, as well as influential nontechnical (managerial, social, and environmental) attributes and their associated design factors into the decision process.

\section{The Proposed Decision Model}

The problem as stated above is, by definition, a Multiple Attribute Decision Making (MADM) problem. A MADM problem [37] usually comprises a finite number of explicitly given alternatives/solutions and a set of performance attributes/criteria. It is acknowledged that the most creative task in making a decision is to choose the factors that are important for that decision, [38].

In the case of prototyping decisions, engineering, managerial, and other influencing issues coexist $[24,39]$.

3.1. Model Structure and Method Implemented. In the proposed approach a structured, inclusive, and updatable list, of such universally recognized engineering and nonengineering issues, is considered as the main group of decision criteria. Together with their associated design factors they are analytically processed in the form of a decision support model, using the Analytic Hierarchy Process (AHP), [40]. Hierarchic Design and Evaluation phases of the AHP have all been properly followed, with the first deriving the structure of the decision tree, consisting of five (5) levels as explained below in the paper and shown in Figure 3, and with the second giving (a) the main design verification priority hierarchy of the design team (higher level criteria), (b) the importance/preference relations between lower levels of criteria and subcriteria, and (c) the grading fields for all considered alternatives to be investigated, as bottom level criteria to be graded by experts against standard rating scales.

This model relies on the expert knowledge of both design team/organization-related and external contributors with expertise on cost, performance and other characteristics of the prototyping alternatives under consideration. Using AHP, they define the importance and preference weights for checking the engineering and nonengineering parameters driving the product design, in the form of Design Attributes (DAs) and their constituting Design Factors (DFs). Altogether they create a "knowledge base," typical of the implementing organization, its operating industrial environment, and its portfolio of products. AHP weights per design stage, prototyping alternative, and design factor are this way assigned, depending on the case under focus, with the model "capturing" a "snapshot" of the current prototyping need and evaluating the alternatives for the given industrial environment.

The outcome is a ranked prioritization between the examined alternatives, with the one presenting the highest score being the most appropriate for the design team.
Figure 4 describes the model conceptual structure. Depending on the product category, certain weights per design stage, attribute, or factor may be applicable to more projects and/or product categories and a "weights database" permitting updating and/or upgrading can be gradually created and exploited over time by the implementing organization.

The presented decision tool enhances and upgrades preceded AHP implementation for prototyping selection, $[34,36,41]$, both in terms of the considered decision criteria and of the prototype realization alternatives considered, in a realistic way and in close contact with the current industrial practice.

3.2. Design Attributes (DAs) and Design Factors (DFs). An extensive list of generic Engineering Parameters Design Attributes (DAs) is given by Dowlatshahi, [16]. The list is partly adopted by the authors in the present work (Table 1). Many of these parameters issues, in the same or in slightly diversified form, are also quoted by Engineering Design authors, [14, 19, 42, 43] and are considered by others as "dimensions of quality" [44] for the majority of new products. They can be further decomposed into associated Design Factors (DFs). Dowlatshahi's list of DFs reaches a total of 179, with some of them appearing in several DAs.

In the present work, in order for the proposed new approach to be effective and comprehensive and bearing in mind the Pareto principle, also known as the " $80-20$ " rule, which states that only a few variables factors of a given problem are responsible for most of the effects on the response, while most variables contribute little, [45], a "filtering" and grouping of both DAs and DFs was performed by the authors. DFs to be included as DA associates in the decision tree of the presented work were limited to 80 , as verifiable by prototypes at early design stages. DAs were then also grouped according to their conceptual affinity to the basic form-fit-function principles of prototyping.

3.3. The "Form-Fit-Function" Classification. Since prototypes are used to verify the PDS of a new product, it is crucial to investigate and distribute these verification preferences for every factor under each of the Design Attributes and also determine the level of importance of each attribute.

Proper practicing of the AHP method dictates a maximum number of seven and definitely no more than nine criteria, in each level of comparisons [40]. Apart from AHP mathematics, this is also justified by the limited ability of the human brain to simultaneously handle in most cases up to seven and rarely up to nine facts or elements of information, without getting confused, [46]. The seventeen (17) DAs of Table 1 were consequently grouped in the proposed model by the authors, according to their conceptual relevance to the cornerstone triad of prototyping, namely, form, fit, and function and then coupled with their associated DAs and DFs of the model, as shown in Table 2.

3.4. Managerial and Other Issues Influencing Prototyping Decisions. To further rationalize the decision model and the decision tree hierarchy, nonengineering issues also have to be 


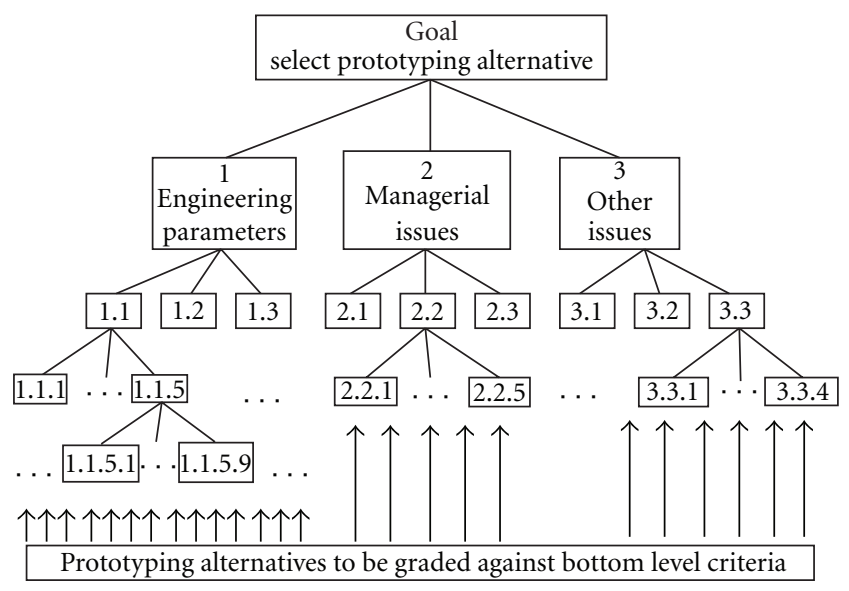

FIgURE 3: Structure of the 5-level decision hierarchy.

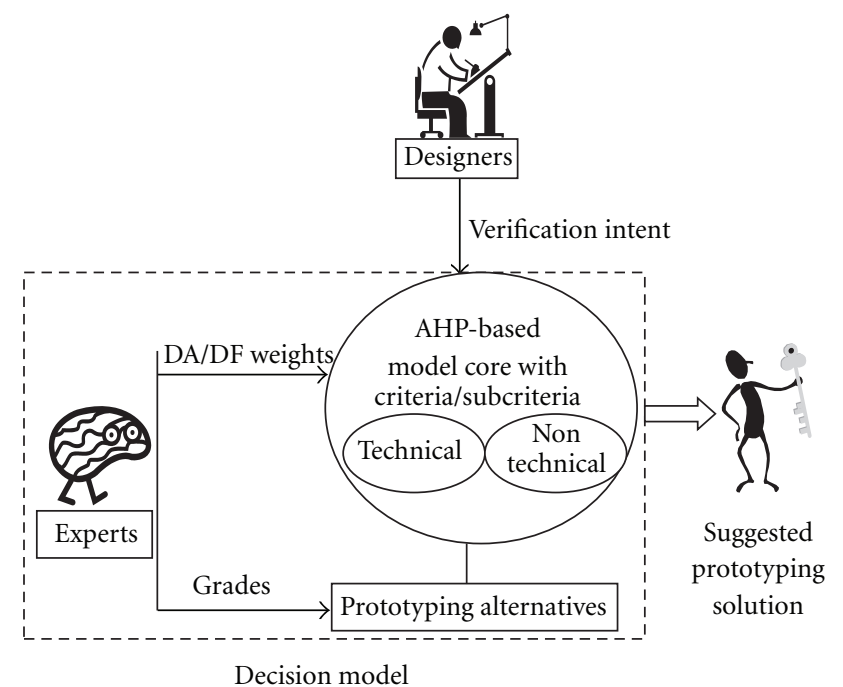

Figure 4: The decision model.

taken into consideration. These are classified by the authors into two major groups: Managerial and Other General issues.

3.4.1. Managerial Issues. They are the most typical "pressure issues" to both engineering and corporate executives, namely, cost, time, and risks. Each one of them is here decomposed by the authors to its main constituting factors, as in Table 3.

3.4.2. Other General Issues. As both society and design have evolved, some new parameters have also come into consideration in every form of engineering and also in prototyping.

Globalization of both markets and industrial activity has introduced social considerations, such as support of
TABLe 1: Design attributes.

\begin{tabular}{lc}
\hline \multicolumn{1}{c}{ Engineering parameters as design attributes (DAs) } \\
\hline$(1)$ & Aesthetics \\
$(2)$ & Capacity \\
$(3)$ & Durability \\
$(4)$ & Ergonomics \\
$(5)$ & Interchangeability \\
$(6)$ & Maintainability \\
$(7)$ & Manufacturability \\
$(8)$ & Marketability \\
$(9)$ & Performance \\
$(10)$ & Reliability \\
$(11)$ & Remanufacturability \\
$(12)$ & Safety \\
$(13)$ & Shedulability \\
$(14)$ & Serviceability \\
$(15)$ & Simplicity \\
$(16)$ & Testability \\
$(17)$ & Transportability
\end{tabular}

an enterprise or group and support of national and local economies.

Environmental considerations are also present, namely, recyclability, minimization of energy consumption (to minimize $\mathrm{CO}_{2}$ emission and prevent "global warming"), and sustainability of the environment. All the above are increasingly taken into account during engineering decisions and are expected to be even more important in the years to come. They are therefore adopted in the presented study and included as an independent decision branch in the proposed model, as in Table 4. 
TABLE 2: Structure of engineering parameters and factors in the proposed approach.

\begin{tabular}{|c|c|c|c|}
\hline $\begin{array}{l}\text { Level } 1 \\
\text { Branch main node }\end{array}$ & $\begin{array}{l}\text { Level } 2 \\
\text { DA groups }\end{array}$ & $\begin{array}{l}\text { Level } 3 \\
\text { DAs of the model }\end{array}$ & $\begin{array}{c}\text { Level } 4 \\
\text { DFs of the model }\end{array}$ \\
\hline \multirow{52}{*}{$\begin{array}{l}\text { 1. Verification of engineering } \\
\text { parameters of the New } \\
\text { product }\end{array}$} & 1.1 Form & 1.1.1 Aesthetics & 1.1.1.1 Shape \\
\hline & & & 1.1.1.2 Size \\
\hline & & & 1.1.1.3 Color \\
\hline & & & 1.1.1.4 Symmetry \\
\hline & & & 1.1.1.5 Incorporation with environment \\
\hline & & & 1.1.1.6 Pattern repetition \\
\hline & & & 1.1.1.7 Social association \\
\hline & & & 1.1.1.8 Critical dimensions \\
\hline & & 1.1.2 Ergonomy & 1.1.2.1 Operating height \\
\hline & & & 1.1.2.2 Ease of function/use \\
\hline & & & 1.1.2.3 Lighting \\
\hline & & & 1.1.2.4 Human/machine interaction \\
\hline & & & 1.1.2.5 Comfort \\
\hline & & & 1.1.2.6 User fatigue \\
\hline & & & 1.1.2.7 Color recognition \\
\hline & & & 1.1.2.8 Anthropometry \\
\hline & & & $\begin{array}{l}\text { 1.1.2.9 Rationale and efficiency of controls and displays } \\
\text { layout }\end{array}$ \\
\hline & & 1.1.3 Simplicity & 1.1.3.1Technology \\
\hline & & & 1.1.3.2 Manufacture \\
\hline & & & 1.1.3.3 Maintenance by user \\
\hline & & & 1.1.3.4 Use \\
\hline & & 1.1.4 Transportability & 1.1.4.1 Lift \\
\hline & & & 1.1.4.2 Move/transport \\
\hline & & & 1.1.4.3 Size overall \\
\hline & & & 1.1.4.4 Packaging \\
\hline & & & 1.1.4.5 Max dimensions \\
\hline & & & 1.1.4.6 Max weight \\
\hline & & & 1.1.4.7 Storage \\
\hline & & & 1.1.4.8 Shipping/travel \\
\hline & & 1.1.5 Manufacturability & 1.1.5.1 Tolerances \\
\hline & & & 1.1.5.2 Surface quality \\
\hline & & & 1.1.5.3 Dimensions \\
\hline & & & 1.1.5.4 Material \\
\hline & & & 1.1.5.5 Production methods and infrastructures \\
\hline & & & 1.1.5.6 Geometry-manufacturing features \\
\hline & & & 1.1.5.7 Space required \\
\hline & & & 1.1.5.8 Production kinematics and forces \\
\hline & & & 1.1.5.9 power requirements \\
\hline & & 1.2.1 Interchangeability & 1.2.1.1 Speed/rapidity \\
\hline & & & 1.2.1.2 Accuracy \\
\hline & & & 1.2.1.3 Versatility/multirole \\
\hline & & & 1.2.1.4 Vertebrate structure/modular \\
\hline & & $\begin{array}{l}\text { 1.2.2 Serviceability/ } \\
\text { Maintainability }\end{array}$ & 1.2.2.1 Surface protection \\
\hline & & & 1.2.2.2 Ease of inspection \\
\hline & & & 1.2.2.3 Ease of repair \\
\hline & & & 1.2.2.4 Average repair time \\
\hline & & $\begin{array}{l}\text { 1.2.3 Recyclability/ } \\
\text { Remanufacturability }\end{array}$ & 1.2.3.1 Disassembly difficulty \\
\hline & & & 1.2.3.2 Wear and wear tolerances of moving parts \\
\hline & & & 1.2.3.3 Impermeable/sealing surfaces \\
\hline & & & 1.2.3.4 Final material recyclability \\
\hline & & & 1.2.3.5 Cleaning requirements \\
\hline & & & 1.2.3.6 Part repair/refurbishment cost \\
\hline
\end{tabular}


TABle 2: Continued.

\begin{tabular}{|c|c|c|c|}
\hline $\begin{array}{c}\text { Level } 1 \\
\text { Branch main node } \\
\end{array}$ & $\begin{array}{c}\text { Level } 2 \\
\text { DA groups }\end{array}$ & $\begin{array}{c}\text { Level } 3 \\
\text { DAs of the model }\end{array}$ & $\begin{array}{c}\text { Level } 4 \\
\text { DFs of the model }\end{array}$ \\
\hline & \multirow{10}{*}{ 1.3 Function } & 1.2.4 Assemblability & 1.2.4.1 Ease of assembly \\
\hline & & & $\begin{array}{l}\text { 1.2.4.2 Assembly axes and directions } \\
\text { 1.2.4.3 Assembly time } \\
\text { 1.2.4.4 Depth of assembly tree }\end{array}$ \\
\hline & & 1.3.1 Durability & 1.3.1.1 Abuse \\
\hline & & & $\begin{array}{l}\text { 1.3.1.2 Misuse } \\
\text { 1.3.1.3 Bandalism } \\
\text { 1.3.1.4 Corrosion } \\
\text { 1.3.1.5 Moisture resistance } \\
\text { 1.3.1.6 Mechanical strength } \\
\text { 1.3.1.7 Resistance to chemicals }\end{array}$ \\
\hline & & 1.3.2 Safety & 1.3.2.1 Electrical \\
\hline & & & $\begin{array}{l}\text { 1.3.2.2 Mechanical } \\
\text { 1.3.2.3 Chemical } \\
\text { 1.3.2.4 Stability } \\
\text { 1.3.2.5 Safety during accident/failure } \\
\text { 1.3.2.6 Sharp edges/bosses }\end{array}$ \\
\hline & & 1.3.3 Reliability & 1.3.3.1 Mean time to first failure (MTTFF) \\
\hline & & & $\begin{array}{l}\text { 1.3.3.2 Mean time between failures }(\mathrm{MTBF}) \\
\text { 1.3.3.3 Failure rate per unit time (FR/UT) } \\
\text { 1.3.3.4 Average function time between failures }\end{array}$ \\
\hline & & 1.3.4 Performance & 1.3.4.1 Size \\
\hline & & & $\begin{array}{l}\text { 1.3.4.2 Force } \\
\text { 1.3.4.3 Motion/movements } \\
\text { 1.3.4.4 Direction } \\
\text { 1.3.4.5 Max speed } \\
\text { 1.3.4.6 Pressure } \\
\text { 1.3.4.7 Temperature } \\
\text { 1.3.4.8 Sound/noise } \\
\text { 1.3.4.9 Flow }\end{array}$ \\
\hline
\end{tabular}

The combination of Tables 2, 3, and 4 in a unified schematic completes all the cells of the overall decision hierarchy as previously presented in Figure 4.

3.5. Role of Experts Rating and Grades of the Alternatives. The functionality of the proposed model as described above and illustrated in Figure 4 is to record the will of the design team, regarding the intended verifications, and to indicate the most appropriate prototyping alternative.

The first task is performed by pairwise comparisons of the decision criteria in the different levels of the model starting from the top and reaching the bottom of the tree.

Each comparison corresponds to a question, such as: "For the intended verification, in a scale of 1 to 9, how important is the validation of function against the validation of form, within engineering parameters?"

This question will determine the relative importance of criterion 1.3 (function) against 1.1 (form) in level 3 of the decision tree, both referring to Node 1 (Engineering Parameters).

A complete set of questions must be answered by expert members of the design team, regarding all criteria, in all levels of Figure 4, each time a prototyping decision has to be made. The synthesis of all criteria and their contribution towards the decision clearly records the verification intent of the design team.

The second task calls for valid assessment of prototyping alternatives against all bottom level criteria. This again has to be performed by experts, this time not necessarily related to the design team, using ratings against all bottom level criteria.

The method of standard rating scales and grades (absolute judgment method) was preferred and applied by the authors because it does not limit the number of participating alternatives. If the assessment of alternatives was instead made with pairwise comparisons (relative judgment), adding a new alternative would every time require a full comparison of it to all other preexisting alternatives, under all bottom level criteria, which of course could not prove very handy.

Using grades and rating scales, each prototyping alternative acquires a characterization according to the scale of rating and a normalized utility grade between 0 and 1 , based on the ratings formulation. A scale can be generally, or specifically descriptive, of the alternative's performance against the criterion under scope. An example of scales and 
TABLE 3: Managerial criteria and factors included in the model.

\begin{tabular}{|c|c|c|}
\hline $\begin{array}{c}\text { Level } 1 \\
\text { Branch main node }\end{array}$ & $\begin{array}{c}\text { Level } 2 \\
\text { Main managerial criteria }\end{array}$ & $\begin{array}{c}\text { Level } 3 \\
\text { Managerial criteria factors }\end{array}$ \\
\hline \multirow[t]{17}{*}{$\begin{array}{l}\text { 2. Managerial issues of } \\
\text { prototyping decisions }\end{array}$} & 2.1 Cost & 2.1.1 Labor cost \\
\hline & & 2.1.2 Overhead and depreciation costs \\
\hline & & 2.1.3 Fabrication/operation cost \\
\hline & & 2.1.4 Consumables cost \\
\hline & & 2.1.5 Cost to rebuild the same \\
\hline & & 2.1.6 Cost to rebuild modified \\
\hline & 2.2 Time & 2.2.1 Preparation/preprocessing \\
\hline & & 2.2.2 Fabrication/operation/processing \\
\hline & & 2.2.3 Finishing \\
\hline & & 2.2.4 Time to rebuild the same \\
\hline & & 2.2.5 Time to rebuild the modified \\
\hline & $\begin{array}{l}\text { 2.3 Method reliability } \\
\text { and risk involved }\end{array}$ & 2.3.1 Repeatability of result \\
\hline & & 2.3.2 Possibility of method failure \\
\hline & & 2.3.3 Impact of method failure \\
\hline & & 2.3.4 Possibility of equipment failure/malfunction \\
\hline & & 2.3.5 Ease of resuming operation/repairing \\
\hline & & 2.3.6 Operators expertise \\
\hline
\end{tabular}

TABLE 4: Other influencing parameters included in the model.

\begin{tabular}{|c|c|c|}
\hline $\begin{array}{l}\text { Level } 1 \\
\text { Branch main } \\
\text { node }\end{array}$ & $\begin{array}{l}\text { Level } 2 \\
\text { Other influencing } \\
\text { parameters/criteria }\end{array}$ & $\begin{array}{l}\text { Level } 3 \\
\text { Factors }\end{array}$ \\
\hline \multirow{11}{*}{$\begin{array}{l}\text { 3. Other issues } \\
\text { influencing } \\
\text { prototyping } \\
\text { decisions }\end{array}$} & \multirow{4}{*}{ 3.1 Environment } & 3.1.1 Energy consumption \\
\hline & & 3.1.2 Materials consumption \\
\hline & & 3.1.3 Materials recyclability \\
\hline & & 3.1.4 Materials toxicity \\
\hline & \multirow{3}{*}{ 3.2 Social Issues } & 3.2.1 Support of national economy \\
\hline & & 3.2.2 Support of local community/economy \\
\hline & & 3.2.3 Support of enterprise/group \\
\hline & \multirow{4}{*}{$\begin{array}{l}3.3 \text { Method } \\
\text { availability }\end{array}$} & 3.3.1 Availability within enterprise/group \\
\hline & & 3.3.2 Establishment/spread of technology/method \\
\hline & & 3.3.3 Existence in local industrial environment \\
\hline & & 3.3.4 Existence in national industrial environment \\
\hline
\end{tabular}

respective utilities for the criteria 1.1.1.2 (size) and 3.3.1 (availability within enterprise/group) is given in Table 5.

The grades, according to the scales that the experts assign to the alternatives, act as a "knowledge base" for the model proposed. They depict on one hand the state of the art for the competing technologies and their performance against the bottom level criteria and on the other hand the conditions within the organization that performs the design and/or prototyping tasks. Grading experts should therefore be very cautiously selected in order for the model to be realistic and trustworthy and they should periodically check and update the values of the grades, according to technological advancements, organizational changes (e.g., purchasing of a new technology), or social changes.

3.6. Model Implementation, Evaluation, and Assessment of Alternatives Application Example. Having an "up-to-date" expert knowledge base in the model, the proposed approach can be implemented each time prototyping is required. Weights of the bottom level criteria are produced with pairwise comparisons and AHP is performed in all levels of the hierarchy. Weights can be expressed both locally for the node of their covering criterion and globally with respect to the overall goal following the decision tree's structure. 
TABLE 5: Examples of rating scales and utility grades.

\begin{tabular}{|c|c|c|c|c|c|c|c|}
\hline \multirow{2}{*}{$\begin{array}{l}\text { Criterion } \\
1.1 .1 .2 \text { Size }\end{array}$} & \multicolumn{7}{|c|}{ Rating scale and utility grade } \\
\hline & Unacceptable & Very bad & Bad & Average & Well & $\begin{array}{l}\text { Very } \\
\text { well }\end{array}$ & Perfect \\
\hline & 0 & 0.1 & 0.3 & 0.5 & 0.7 & 0.8 & 1 \\
\hline \multirow{2}{*}{$\begin{array}{l}\text { 3.3.1 Availability } \\
\text { within } \\
\text { enterprise/group }\end{array}$} & \multicolumn{2}{|c|}{ Not Available } & & $\begin{array}{l}\text { le with } \\
\text { t of site) }\end{array}$ & \multicolumn{2}{|c|}{$\begin{array}{c}\text { Available upon request } \\
\text { and after scheduling }\end{array}$} & $\begin{array}{l}\text { Directly } \\
\text { available }\end{array}$ \\
\hline & \multicolumn{2}{|c|}{0} & \multicolumn{2}{|c|}{0.35} & \multicolumn{2}{|c|}{0.7} & 1 \\
\hline
\end{tabular}

TABLE 6: Prototyping alternatives of the model.

\begin{tabular}{ll}
\hline & Alternatives included in the decision model \\
\hline$(1)$ & 3D CAD models \\
$(2)$ & 3D CAD models combined with FEA \\
$(3)$ & 3D CAD models combined with FEA and CAM \\
$(4)$ & Full PLM of the product \\
$(5)$ & Desktop stereoscopic VP \\
$(6)$ & Desktop stereoscopic VP with haptic feedback \\
$(7)$ & CAVE stereoscopic VP \\
$(8)$ & CAVE stereoscopic VP with haptic feedback \\
$(9)$ & Handcrafted models \\
$(10)$ & Conventionally machined models \\
$(11)$ & Desktop CNC prototypes \\
$(12)$ & Large CNC prototypes \\
$(13)$ & Desktop RP prototypes \\
$(14)$ & Resin-based RP prototypes \\
$(15)$ & Solid sheet-based RP prototypes \\
$(16)$ & Powder-based RP prototypes \\
$(17)$ & Metal-based RP prototypes \\
$(18)$ & Deposition-based RP prototypes \\
$(19)$ & RP prototypes in general combined with RT techniques \\
$(20)$ & Technical prototypes which, although not applicable \\
& at early design, are included for assessment as the best \\
\hline
\end{tabular}

Synthesis of the overall grade for prototyping alternatives ultimately yields their ranking order with respect to the goal.

The decision model of the new approach proposed in this paper was realized through the dedicated AHP software Expert Choice v.11, under Microsoft Windows.

The structure of the model was built in the software and it was tested in several cases.

The prototyping alternatives included in the test model were the ones of Table 6.

Descriptive rating scales were created for all of the 109 bottom level criteria included in the model and the alternatives were graded according to the scale of each criterion by external expert advice seeked by the authors. The grades assigned well correspond to the conditions of the Hellenic industrial environment at the time of the study, whereas the National Technical University of Athens was, for the sake of the test model, supposed to be in the role of the industrial operator seeking prototyping alternatives.

$\begin{array}{ll}\text { 3D CAD models } & 0.045 \\ \text { 3D CAD models with FEA } & 0.048 \\ \text { Virtual prototyping (stereoscopic desktop) } & 0.054 \\ \text { Virtual prototyping (stereoscopic cave) } & 0.053 \\ \text { Virtual prototyping with haptic feedback desktop } & 0.055 \\ \text { Virtual prototyping with haptic feedback cave } & 0.058 \\ \text { Prototype handcrafted } & 0.064 \\ \text { Conventional prototype with material removal } & 0.072 \\ \text { Conventional prototype with CNC material removal } & 0.076 \\ \text { CNC desktop prototype } & 0.066 \\ \text { Desktop rapid prototype } & 0.065 \\ \text { Resin-based RP } & 0.066 \\ \text { Powder-based RP } & 0.064 \\ \text { Solid sheet-based RP } & 0.07 \\ \text { Deposition-based RP } & 0.067 \\ \text { Rapid prototypes and rapid tooling } & 0.077\end{array}$

Figure 5: Overall results for geometrical prototype of thermoplastic product.

For test model implementation, a geometrical prototype solution was seeked, to be used during the embodiment and detailed design phases of NPDD for a typical thermoplastic product (plastic casings of a desktop clock-radio).

A selection of prototyping alternatives from Table 6 was considered for evaluation, namely, numbers $1,2,5,6,7,9$, $10,11,12,13,14,15,16,18$, and 19.

The finally obtained method suitability grading is given in Figure 5. It can be seen that Rapid Prototyping and Tooling has come out as the most appropriate one for this particular case study closely followed by CNC machined models.

It is worth noting that the user is directed to use RP and RT techniques, in accordance with the distribution of priorities he has already recorded within the model, as shown in Figure 6. The dominant priorities, which up to a point are further analyzed in the same figure, realistically correspond to the verification intent of the plastic casing through a geometrical prototype.

To better highlight the result, let us suggest that the importance of the three basic decision criteria (first three nodes) of Figure 6 was set to be of equal value ( 0.333 each). Then the test model would result in that $3 \mathrm{D}$ CAD models would prevail as the most appropriate solution, with combined RP and RT ranking 8th; but this would be an unrealistic prioritization for the case of a geometrical 


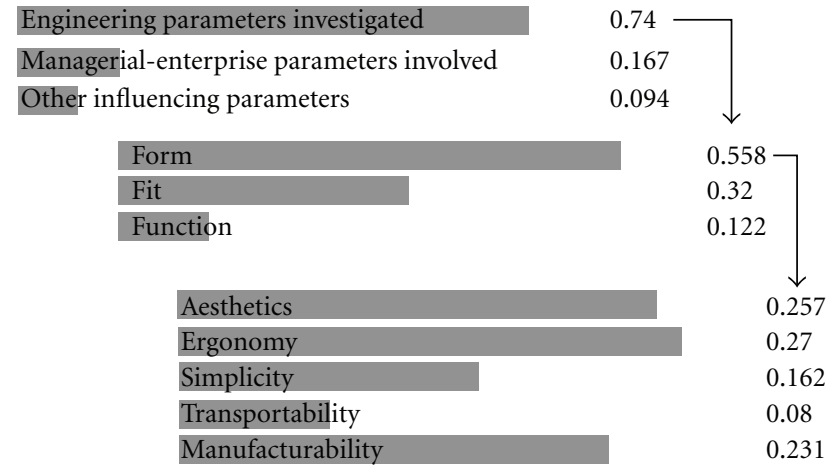

FIgURe 6: Main distribution of priorities.

prototype like the one required in the example and therefore rather unlikely to be assigned by the test model utilizing designers.

\section{Discussion}

4.1. Innovative Features of the Model. The presented model introduces an enhanced, innovative, and realistic AHP-based decision tool to provide a reliable and documented solution to the multiattribute decision problem of selecting not only between specific prototyping systems and machines but in a broader sense between prototype capable modern design technological alternatives, during the early stages of a new product development process.

In an integrated manner, it takes into consideration both engineering and nonengineering criteria that definitely exist in such decisions and records expert assigned ratings and grades per design stage. The latter can always be edited and/or updated and referenced for future new designs. Environmental and social issues and criteria are also successfully addressed and incorporated in the model.

Engineering parameters as issues and criteria of the proposed approach include a wide range of competently recognized design attributes and design factors. Furthermore these engineering parameters are grouped and handled under the scope of the three most fundamental concepts of prototyping utilities, form, fit, and function.

Handling of qualitative as well as quantitative issues is possible and the system is open for upgrading or additions of criteria or alternatives and readily applicable by design teams of any industrial environment, just after an initial grading done by related experts.

4.2. Areas and Ways of Application. The proposed decision model is applicable by any organization involved in new mechanical product development, either SME or a large enterprise. It can be implemented several times during the different stages of the NPDD process.

Bottom level grades of alternatives will act as a constant "knowledge base" representing the current state of the art for existing prototyping alternatives/technologies and for the industrial status of the implementing organization.
Another "knowledge base" aspect of the proposed model lies within prerecorded priority rankings, which can be created by using the proposed model respective to product categories and families of the implementing company. Then, in future uses of the model, the design team can be able to directly select such a "priority template," verify or slightly modify its prototyping intents and restrictions, and fast arrive to a decision simply by following the model's structure.

4.3. Benefits of Implementing the Decision Model. Industrial operators willing to adopt and consistently use the proposed model are expected to benefit from the following.

(i) Substantiated rational prototyping decisions, independent of the decision maker executive, based on the truly most important engineering parameters and attributes of their new products and suited to the current status of their organization and industrial environment.

(ii) Procedural standardization, reduction of fuzziness, and increased repeatability of prototyping decisions.

(iii) By long-term application, mapping of the requirements from different types of prototypes of several product families, according to the way that new product development is practiced within the specific organization.

(iv) An overall increase of prototyping efficiency, leading to less prototyping and iteration cycles, with apparent cost and time savings.

(v) Risk reduction both for successful prototyping tasks and for the overall product quality evaluation.

4.4. Possible Enhancements, Improvements, and Integration of the Model. The proposed model, once incorporated in the curriculum of specific design teams, could be enriched with more parameters in any of its levels of criteria or omit others that prove to have little or none influence for specific organizations or specific products. It can also be further analyzed by its users in more detailed levels of influencing factors, tailored to the needs and characteristics of certain product families, products, and components.

Another possible enhancement is the integration of the model with relational databases, containing actual vendors, bureaus, technologies, machines, and software to perform the prototyping tasks. In a second decision step, the user could then be assisted to select not only families or classes of prototyping solutions but also specific machines and systems in situ or at a service bureau, based on actual values of product parameters, such as overall dimensions, tolerances on specific critical dimensions, surface quality, and engineering materials.

Finally, testing the group of engineering and nonengineering criteria and prototype class alternatives adopted in this work, also with other MADM methods like the TOPSIS method to include fuzziness in the decision process, and comparing the results with the ones of the present work could prove interesting. 


\section{Conclusion}

The proposed model attempts to provide a reliable and documented solution to the multiattribute decision problem of selecting between prototyping alternatives, during the early stages of the new mechanical product development process.

It grounds on the Analytic Hierarchy Process for formulating the problem and is based on several decision parameters and engineering attributes, with the latter being grouped under the fundamental concepts of prototyping, namely, form, fit, and function verification.

It is not intended to be the prototyping panacea tool, just a first step towards the most promising of prototyping solutions. In order for it to be effective, it has to rely on the advice of experts who are as close as possible to the environment of the users and to the state of art of the technologies and it should get periodically updated and ought to be implemented with caution and consistency by the design team representatives.

It shows a future perspective, especially if integrated with other selection and decision support methodologies, such as relational databases.

\section{References}

[1] A. E. Cha, "China exports down 25 percent," Washington Post, March 2009.

[2] A. Faiola, "European slump may stall global rebound," Washington Post, May 2009.

[3] S. Pearlstein, "Europe, Asia find their supply chains yanked. Beware the backlash," Washington Post, February 2009.

[4] OECD, Trade and Economic Effects of Responses to the Economic Crisis, OECD Trade Policy Studies, OECD Publishing, 2010.

[5] P. Rochus, J. Y. Plesseria, M. Van Elsen, J. P. Kruth, R. Carrus, and T. Dormal, "New applications of rapid prototyping and rapid manufacturing (RP/RM) technologies for space instrumentation," Acta Astronautica, vol. 61, no. 1-6, pp. 352$359,2007$.

[6] Y. S. Liao, H. C. Li, and M. T. Chen, "The study of rapid prototyping process with embedded functional inserts," Journal of Materials Processing Technology, vol. 192-193, pp. 68-74, 2007.

[7] S. H. Choi and H. H. Cheung, "A versatile virtual prototyping system for rapid product development," Computers in Industry, vol. 59, no. 5, pp. 477-488, 2008.

[8] L. Sass, "A physical design grammar: a production system for layered manufacturing machines," Automation in Construction, vol. 17, no. 6, pp. 691-704, 2008.

[9] S. Ha, L. Kim, S. Park, C. Jun, and H. Rho, "Virtual prototyping enhanced by a haptic interface," CIRP Annals Manufacturing Technology, vol. 58, no. 1, pp. 135-138, 2009.

[10] H. Lan, "Web-based rapid prototyping and manufacturing systems: a review," Computers in Industry, vol. 60, no. 9, pp. 643-656, 2009.

[11] H. Park, H. C. Moon, and J. Y. Lee, "Tangible augmented prototyping of digital handheld products," Computers in Industry, vol. 60, no. 2, pp. 114-125, 2009.

[12] Y. Zhang and H. Liu, "Application of rapid prototyping technology in die making of diesel engine," Tsinghua Science \& Technology, vol. 14, no. 1, pp. 127-131, 2009.

[13] S. Kumar and J. P. Kruth, "Composites by rapid prototyping technology," Materials and Design, vol. 31, no. 2, pp. 850-856, 2010.

[14] K. T. Ulrich and S. D. Eppinger, Product Design and Development, McGraw Hill, New York, NY, USA, 4th edition, 2008.

[15] R. Stark, F. -L. Krause, C. Kind et al., "Competing in engineering design-the role of virtual product creation," CIRP Journal of Manufacturing Science and Technology, vol. 3, no. 3, pp. 175-184, 2010.

[16] S. Dowlatshahi, "A morphological approach to product design in a concurrent engineering environment," The International Journal of Advanced Manufacturing Technology, vol. 9, no. 5, pp. 324-332, 1994.

[17] K. H. Grote, M. L. Walo, and J. L. Miller, "Manufacturing and product development in the USA, in particular in the Los Angeles Basin and the strategic training and implementation of high manufacturing technology," Integrated Manufacturing Systems, vol. 9, no. 4, pp. 228-235, 1998.

[18] S. O. Onuh and Y. Y. Yusuf, "Rapid prototyping technology: applications and benefits for rapid product development," Journal of Intelligent Manufacturing, vol. 10, no. 3, pp. 301311, 1999.

[19] G. Pahl, W. Beitz, J. Feldhusen, and K. H. Grote, Engineering Design: A Systematic Approach, Springer, London, UK, 3rd edition, 2007.

[20] F. Zorriassatine, C. Wykes, R. Parkin, and N. Gindy, "A survey of virtual prototyping techniques for mechanical product development," Proceedings of the Institution of Mechanical Engineers, Part B: Journal of Engineering Manufacture, vol. 217, no. 4, pp. 513-530, 2003.

[21] Y. Ding, H. Lan, J. Hong, and D. Wu, "An integrated manufacturing system for rapid tooling based on rapid prototyping," Robotics and Computer-Integrated Manufacturing, vol. 20, no. 4, pp. 281-288, 2004.

[22] M. M. Andreasen and C. H. Gudnason, "Planning and integration of product development," in Handbook of Industrial Engineering, G. Salvendy, Ed., chapter 45, p. 1185, WileyInterscience Publication, Institute of Industrial Engineers, New York, NY, USA, 2nd edition, 1992.

[23] D. G. Ullman, The Mechanical Design Process, McGraw-Hill, New York, NY, USA, 1997.

[24] P. G. Maropoulos and D. Ceglarek, "Design verification and validation in product lifecycle," CIRP Annals Manufacturing Technology, vol. 59, no. 2, pp. 740-759, 2010.

[25] D. J. De Beer, L. J. Barnard, and G. J. Booysen, "Threedimensional plotting as a visualisation aid for architectural use," Rapid Prototyping Journal, vol. 10, no. 2, pp. 146-151, 2004.

[26] W. Konig, W. Eversheim, I. Celi, S. Noken, and C. Ullmann, "Rapid Prototyping-Bedarf und Potentiale," VDI-Zeitschrift, vol. 135, no. 8, pp. 92-97, 1993.

[27] D. Atkinson, Rapid Prototyping \& Tooling-A Practical Guide, Strategy Publications, Weltech Centre, Ridgeway, Welwyn Garden City, UK, 1997.

[28] C. K. Chua, K. H. Hong, and S. L. Ho, "Rapid tooling technology-part 1: a comparative study," International Journal of Advanced Manufacturing Technology, vol. 15, no. 8, pp. 604-608, 1999.

[29] C. K. Chua, K. H. Hong, and S. L. Ho, "Rapid tooling technology-part 2: a case study using arc spray metal tooling," International Journal of Advanced Manufacturing Technology, vol. 15, no. 8, pp. 609-614, 1999.

[30] A. Gomes De Sá and G. Zachmann, "Virtual reality as a tool for verification of assembly and maintenance processes," 
Computers \& Graphics, vol. 23, no. 3, pp. 389-403, 1999.

[31] D. T. Pham and S. S. Dimov, Rapid Manufacturing: The Technologies \& Applications of Rapid Prototyping and Rapid Tooling, Springer, London, UK, 2001.

[32] J. S. Bao, Y. Jin, M. Q. Gu, J. Q. Yan, and D. Z. Ma, "Immersive virtual product development," Journal of Materials Processing Technology, vol. 129, no. 1-3, pp. 592-596, 2002.

[33] R. V. Rao and K. K. Padmanabhan, "Rapid prototyping process selection using graph theory and matrix approach," Journal of Materials Processing Technology, vol. 193, no. 1-3, pp. 81-88, 2007.

[34] A. Armillotta, "Selection of layered manufacturing techniques by an adaptive AHP decision model," Robotics and ComputerIntegrated Manufacturing, vol. 24, no. 3, pp. 450-461, 2008.

[35] M. Ancáu and C. Caizar, "The computation of Paretooptimal set in multicriterial optimization of rapid prototyping processes," Computers \& Industrial Engineering, vol. 58, no. 4, pp. 696-708, 2010.

[36] A. Borille, J. Gomes, R. Meyer, and K. Grote, "Applying decision methods to select rapid prototyping technologies," Rapid Prototyping Journal, vol. 16, no. 1, pp. 50-62, 2010.

[37] P. Sen and J. B. Yang, Multiple Criteria Decision Support in Engineering Design, Springer, London, UK, 1998.

[38] T. L. Saaty, "How to make a decision: the analytic hierarchy process," European Journal of Operational Research, vol. 48, no. 1, pp. 9-26, 1990.

[39] Q. Zhang, M. A. Vonderembse, and M. Cao, "Product concept and prototype flexibility in manufacturing: implications for customer satisfaction," European Journal of Operational Research, vol. 194, no. 1, pp. 143-154, 2009.

[40] T. L. Saaty, The Analytic Hierarchy Process, McGraw-Hill, New York, NY, USA, 1980.

[41] T. S. Li and H. H. Huang, "Applying TRIZ and Fuzzy AHP to develop innovative design for automated manufacturing systems," Expert Systems with Applications, vol. 36, no. 4, pp. 8302-8312, 2009.

[42] S. Pugh, Total Design, Addison-Wesley, Wokingham, UK, 1990.

[43] G. Pahl and W. Beitz, Engineering Design, translated by K. Wallace, Springer, New York, NY, USA, 1984.

[44] D. A. Garvin, "Competing on the eight dimensions of quality," Harvard Business Review, vol. 65, no. 6, pp. 101-109, 1987.

[45] L. Trocine and L. C. Malone, "Finding important independent variables through screening designs: a comparison of methods," in Proceedings of the Winter Simulation Conference (WSC '00), J. A. Joines, R. R. Barton, K. Kang, and P. A. Fishwick, Eds., vol. 1, pp. 749-754, Orlando, Fla, USA, 2000.

[46] G. A. Miller, "The magical number seven, plus or minus two: some limits on our capacity for processing information," Psychological Review, vol. 63, no. 2, pp. 81-97, 1956. 

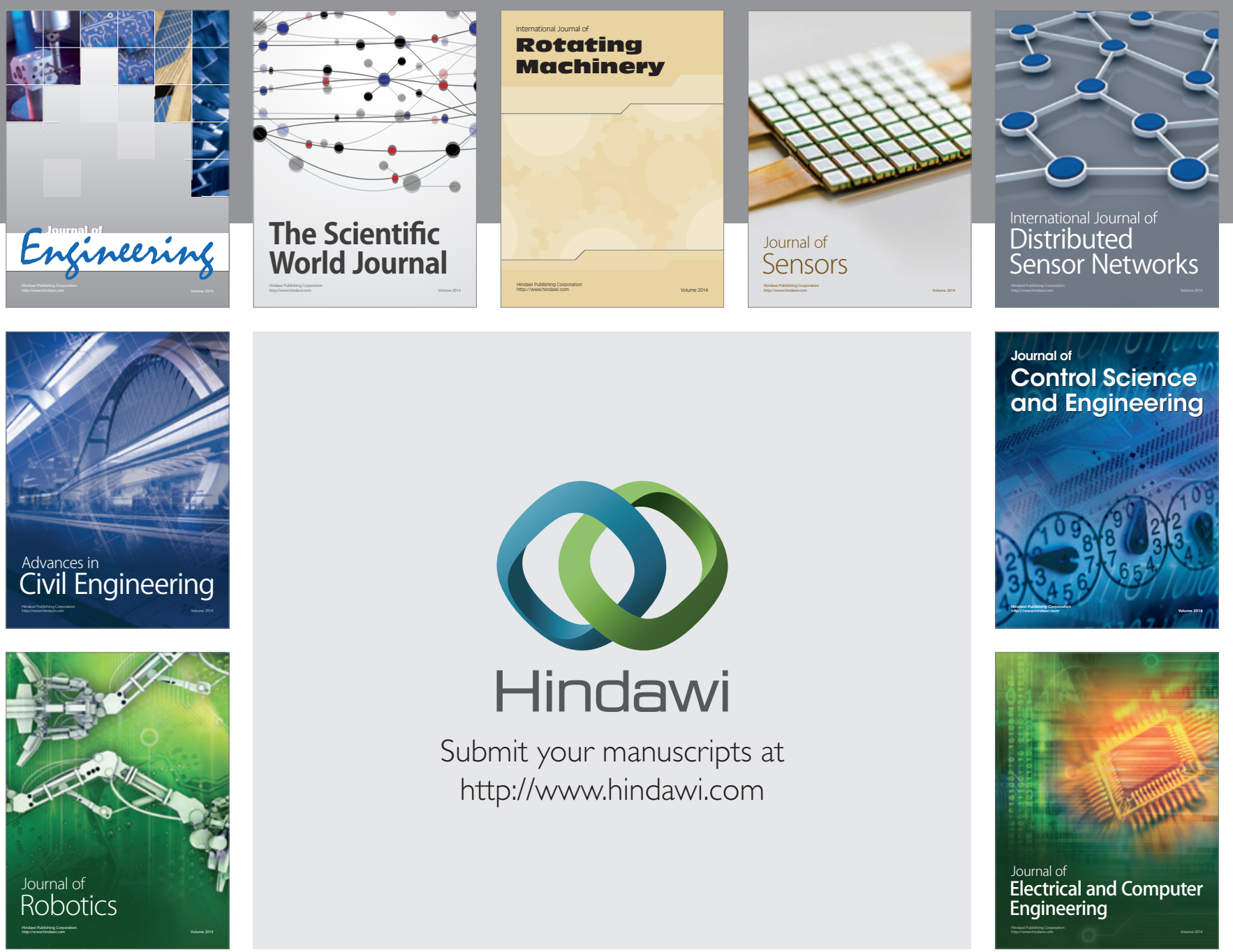

Submit your manuscripts at

http://www.hindawi.com
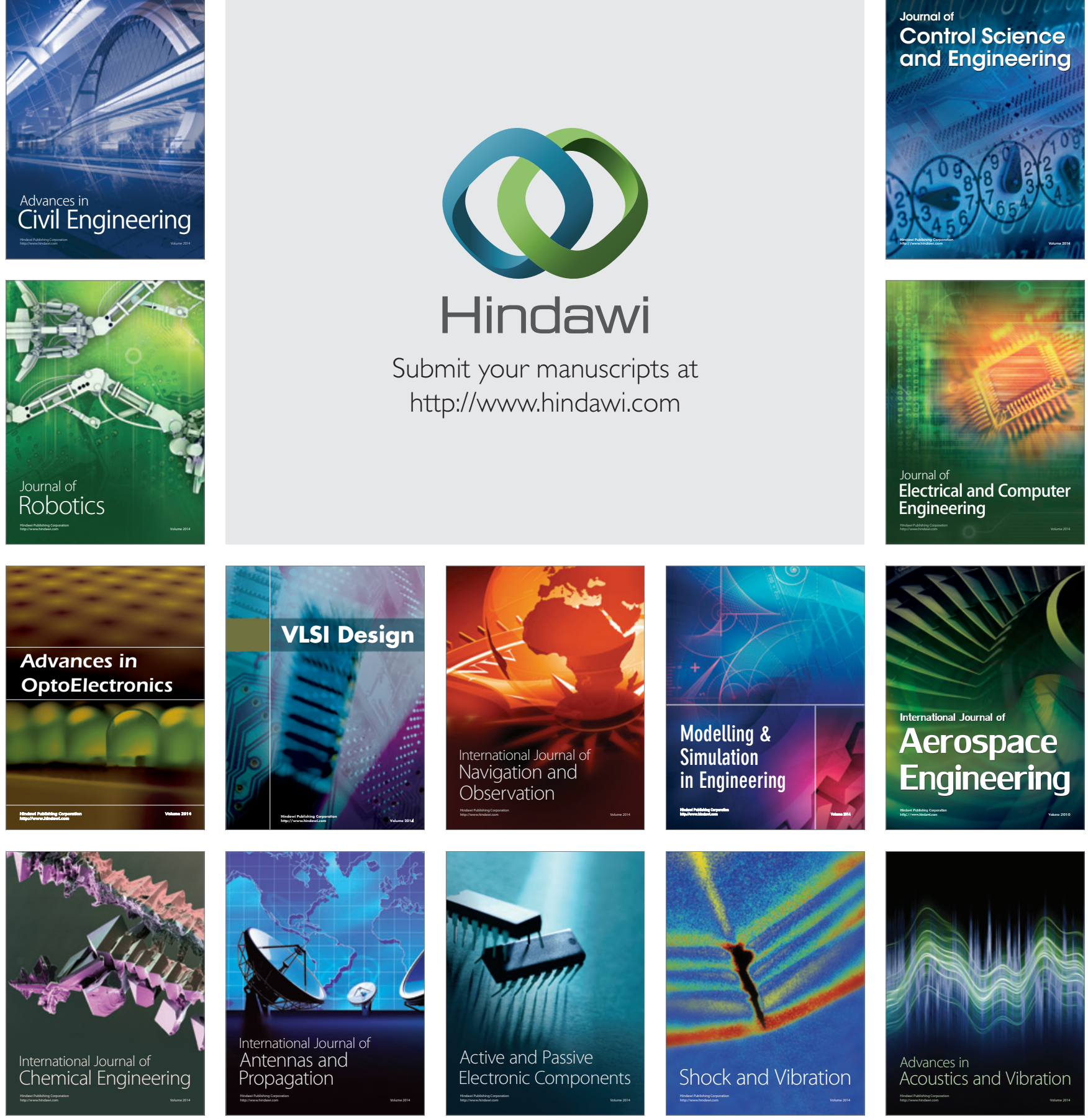